Brit. F. industr. Med., 1967, 24, 255

\title{
Assessing the Heat Stress and Establishing the Limits for Work in a Hot Mine
}

\author{
C. H. WYNDHAM, A. McD. ALLAN, G. A. G. BREDELL, and R. ANDREW \\ From the Human Sciences Laboratory, fohannesburg, South Africa, and Mount Isa Mines Limited, Queensland, \\ Australia
}

The management of the mine at Mount Isa, Queensland, Australia decided to enquire into the following questions with regard to men working underground in hot conditions:

(a) Which of the various heat stress indices predicts most accurately the effects on workmen of the various heat stress factors which occur in the mine at Mount Isa?

(b) How best should the limits of heat stress be judged at which the normal 8-hour shift should be reduced to a 6-hour shift, or at which work should be stopped?

With these objects in mind, oral temperatures were measured on 86 workmen after three hours of ordinary work in the mine and also on 36 occasions on 29 volunteers after three hours of stepping on and off a stool at a work rate of $1,560 \mathrm{ft}$. $\mathrm{lb}$. $/ \mathrm{min}$. These men were studied in different environmental heat stresses over the range that occurs in the mine. Dry bulb air temperatures (D.B.), wet bulb temperatures (W.B.), velocity of air movements, and globe temperatures (G.T.) were measured in the micro-climate in which each man worked. An estimate was made of the work rate of the 86 workmen. From these estimates and measurements, the predicted 4-hourly sweat rate $\left(P_{4} S R\right)$ and corrected effective temperature (C.E.T.) values were determined for each heat stress condition. $P_{4} S R$ values varied between 0.9 and 6.5 and C.E.T. between $70^{\circ}$ and $95^{\circ} \mathrm{F}$.

Correlation coefficients were calculated between oral temperatures and W.B.s, C.E.T.s, and $\mathrm{P}_{4}$ SRs and are $0.51,0.64$, and 0.75 respectively. Further analysis was confined to C.E.T. and $\mathbf{P}_{\mathbf{4}}$ SR. Plots of oral temperature on $\mathrm{P}_{4} \mathrm{SR}$ for conditions where G.T. was more than $10^{\circ} \mathrm{F}$. above D.B. were found to fall well below the rest of the plots, indicating that $P_{4} S R$ exaggerates the effect of mean radiant temperature. These data were therefore excluded from the rest of the analysis. Regression equations were calculated for oral temperature on $\mathrm{P}_{4} S R$ and for oral temperature on C.E.T. for (a) men 'on the job', for (i) conditions where D.B. was more than $10^{\circ} F$. above W.B. and (ii) for conditions where D.B. was less than I0 ${ }^{\circ} \mathrm{F}$. above W.B., and $(b)$ for men 'stepping'. This analysis showed that one overall regression line can be used for all three conditions for oral temperature on $\mathrm{P}_{4} \mathrm{SR}$, but for oral temperature on C.E.T. at least two different regression lines would be needed. Also the correlation coefficients between oral temperature and $\mathrm{P}_{4} S R$ were generally higher than between oral temperature and C.E.T. For the prediction of oral temperature in the mine at Mount Isa the $P_{4} S R$ index is to be preferred to the C.E.T. scale.

These results indicate that the emphasis given to G.T. in the $P_{4} S R$ index is too great. A multi-variance analysis of the $P_{4} S R$ index shows that, in the middle of the range of heat stress conditions examined, a unit change in $P_{4} S R$ would be obtained by about the same change in W.B. and G.T. This is at variance with the present results and also with the experimental findings of the M.R.C. Climatic Physiology Unit at Singapore. It appears, therefore, that the $\mathrm{P}_{4} \mathrm{SR}$ index should be revised in this regard.

When it came to setting limits of heat stress for a 6-hour shift and for 'stop-work', it was decided to base the limit for the 6-hour shift on a I : I00 probability of men reaching an oral temperature of $100 \cdot 5^{\circ} \mathrm{F}$. (rectal temperature of $10 \mathrm{I} \cdot 5^{\circ} \mathrm{F}$.) and to base the 'stop-work' limit on a $\mathrm{I}: 2,000$ probability of reaching an oral temperature of $\mathrm{ror} \cdot 5^{\circ} \mathrm{F}$. (rectal temperature of $102.5^{\circ} \mathrm{F}$.). The reasons for this choice of physiological criteria are given in full in the paper. $P_{4} S R$ values at which these limits are reached were determined by calculating $I: 100$ and $I: 2,000$ probability belts to the overall regression line of oral temperature on $\mathrm{P}_{4} \mathrm{SR}$. The $P_{4} S R$ value at the intersection of the $1: 100$ probability limit and the oral temperature of $100 \cdot 5^{\circ} \mathrm{F}$. is 3.8 and the $P_{4} S R$ value at the intersection of the $1: 2,000$ probability limit and the oral temperature of 
IOI $\cdot 5^{\circ} \mathrm{F}$. is 5.0 . These then are the limits of heat stress in the mine at Mount Isa for a 6-hour shift and for 'stop-work'.

A simple graphical method has been developed and is in use in the mine for determining when the level of work and environmental heat stress have reached either a $\mathrm{P}_{4} \mathrm{SR}$ value of $3 \cdot 8$, when the shift is reduced to six hours; or, when the heat stress has reached a $P_{4} S R$ value of $5 \cdot 0$, when work is stopped.

In the mine at Mount Isa in Queensland, Australia there are some working places underground with relatively high air temperatures and humidities and others with high temperatures of the surface of recently broken rock. The management of the mine decided to enquire into the following questions with regard to men working in these hot conditions:

(a) Which of the various heat stress indices available predicts most accurately the effects on workmen of the various heat stress factors which occur underground in the mine at Mount Isa?

(b) How best should the limits of heat stress be judged at which the normal 8-hour shift should be reduced to a 6-hour shift, or at which work should be stopped?

A great deal has been written about the methods of assessing the stress of work under hot conditions and of the criteria that should be used for determining the limits of heat stress for work in hot conditions (Eichna, Ashe, Bean, and Shelley, 1945; Robinson, Turrell, and Gerking, 1945; Bedford, 1946; Dunham, Holling, Ladell, McArdle, Scott, Thomson, and Weiner, 1946; Belding and Hatch, 1955; Weiner and Lind, 1955; Lind, 1960; Macpherson, 1962; Lind, 1963; Lavenne, 1965; Wyndham, 1965b; Wyndham, Strydom, Morrison, Williams, Bredell, Maritz, and Munro, 1965; Wyndham, Strydom, Morrison, Munro, Heyns, and Sichel, 1966). Nearly all the conclusions are based upon experiments in hot rooms on subjects who were artificially acclimatized to heat and who are, in general, quite different from the ordinary workmen in hot industries with respect to age, physical fitness, health, nutrition, and state of acclimatization. It is doubtful, therefore, whether the conclusions based upon hot room studies can be applied in the practical work situation.

In order to avoid these difficulties a field survey was carried out underground in the mine at Mount Isa in which, firstly, oral temperatures and microclimates were measured and work rates were estimated of 86 miners at the third hour of the shift in various working places which covered the range of air conditions in the mine. Secondly, oral temperatures and microclimates of 29 volunteer miners

Received for publication January 17, 1967. were measured on 36 different occasions after three hours of stepping on and off blocks of wood which were adjusted in height so that each man worked at a moderate rate. These studies were also carried out over a range of air conditions.

From the environmental measurements and the estimated work rates the corrected effective temperatures (C.E.T.s) and predicted 4-hour sweat rates $\left(\mathrm{P}_{4} \mathrm{SRs}\right)$ were determined for each heat stress condition. Oral temperatures were then plotted against C.E.T.S and $\mathrm{P}_{4}$ SRs, regression lines were fitted to the plots, and statistical calculations were made in order to determine which of the two heat stress indices was the better predictor of oral temperature. As a result of this work it was possible to advise the management of the mine which of the heat stress indices should be used and also when a 6-hour shift should be worked and when work should stop.

This is the first time, of which we are aware, that any attempt has been made to apply in the practical working places in a mine the methods which have been developed in climatic chambers for assessing heat stress and for establishing the limits of heat stress for work in hot conditions. The procedures used are described and the conclusions reached are reported because they may have an application for the same purpose in other hot industries.

\section{Methods}

Oral Temperature Measurements The men, working in the area where the day's study was to be carried out, were briefed on the objects of the experiment and on the procedures to be carried out before they went underground. Their oral temperatures were measured soon after arrival at their working places and again each hour for the first three hours of the shift. The men were asked to refrain from drinking any water for the half hour before the oral temperatures were measured.

A test was made to see how the third hour oral temperatures compared with measurements made later in the shift. To check this point the oral temperatures of 26 men were measured at the usual third hour period and again in the afternoon, two hours after the end of 'crib time' (relaxation time).

Air Conditions and Work Rates At the same time as oral temperatures were recorded, measurements of the men's working places were made with a sling psychrometer of wet- (W.B.) and dry-bulb (D.B.) 
temperatures, of the temperature inside a blackened 6-in. copper sphere (G.T.), and of the wind velocity (W.V.), using a hot wire anemometer.

The distribution of the 86 workmen in the various air conditions underground is indicated in Table $I$.

Work rates of the various tasks were estimated by a physiologist with considerable experience in the measurement of work rates of various underground mining tasks in South African gold mines. Some of the important types of work in Mount Isa mine can be divided into the following categories:

\section{'Mucking'}

(I) Scraper working This included some of the hardest work in the worst conditions, i.e., placing scraper pins and scraper blocks on top of newly fired muck pile. Ventilation conditions are seldom good. This operation involves work in restricted places where considerable heat is present plus high humidity-from watering down. Any temporary ventilation put up at this time has to be taken down again prior to scraping and hence is seldom properly installed. This operation lasts a limited time, say, from 15 to 30 minutes.

(2) Machine working Three types of vehicle were used - T4G, track shovel, and air shovel. These are all driven by means of compressed air, and driving involves little more than standing on a platform and manipulating a few levers which offer little resistance. If breakdowns occur then harder work may be involved.

(3) Hand-mucking Ordinary shovelling can be regarded as hard work. It is generally carried out only at long intervals and for a few minutes. It is done (a) to work down to expose $3 \mathrm{ft}$ of face when boring pin holes for placing blocks (to check for misfires), and (b) to 'muck' out last bits from the face after machine working-a short period of intensive effort.

TABLE I

Numbers of Men Studied 'ON THE Job'

\begin{tabular}{|c|c|c|c|c|c|c|c|c|c|c|c|c|c|c|c|c|c|c|c|c|c|c|}
\hline \multirow{3}{*}{$\overbrace{\text { j.T. }\left({ }^{\circ} F .\right)}$} & \multirow[b]{3}{*}{$\begin{array}{l}D . B .\left({ }^{\circ} F .\right) \\
W . B .\left({ }^{\circ} F .\right)\end{array}$} & \multicolumn{20}{|c|}{ Wind Velocity ( $f$ t./min.) } & \multirow{3}{*}{ No. } \\
\hline & & \multicolumn{5}{|c|}{$0-100$} & \multicolumn{5}{|c|}{$100-200$} & \multicolumn{5}{|c|}{$200-300$} & \multicolumn{5}{|c|}{$>300$} & \\
\hline & & $70-$ & $75-$ & $80-$ & $85-$ & 90 & $70-$ & $75-$ & $80-$ & $85-$ & ${ }_{90}^{>}$ & $70-$ & $75-$ & $80-$ & $85-$ & $\begin{array}{l}>0 \\
90\end{array}$ & $70-$ & $75-$ & $80-$ & $85-$ & ${ }_{90}^{>}$ & \\
\hline $70-80$ & $\begin{array}{c}70-80 \\
80-90 \\
90-100 \\
100-110 \\
>110\end{array}$ & & & & & & 2 & & & & & & & & & & & & & & & 2 \\
\hline $80-90$ & $\begin{array}{c}70-80 \\
80-90 \\
90-100 \\
100-110 \\
>110\end{array}$ & & & & & & 2 & & & & & & & & & & & 2 & & & & 4 \\
\hline i $90-100$ & $\begin{array}{c}70-80 \\
80-90 \\
90-100 \\
100-110 \\
>110 \\
\end{array}$ & & 2 & 7 & & & & 5 & $\begin{array}{l}\text { I } \\
4\end{array}$ & $\begin{array}{l}5 \\
6\end{array}$ & & & 2 & & 3 & & & & & & & 35 \\
\hline ioo-110 & $\begin{array}{c}70-80 \\
80-90 \\
90-100 \\
100-110 \\
>110\end{array}$ & & & $\begin{array}{l}2 \\
2 \\
3\end{array}$ & $\mathbf{I}$ & & & 2 & 3 & $\mathbf{I}$ & & & & 2 & 4 & & 1. & & & & & 20 \\
\hline $110-120$ & $\begin{array}{c}70-80 \\
80-90 \\
90-100 \\
100-110 \\
>\text { I I0 }\end{array}$ & & & 2 & 2 & & & & & & 3 & & & $\begin{array}{l}2 \\
2 \\
1\end{array}$ & & & & & $\mathbf{I}$ & & & 13 \\
\hline$>120$ & $\begin{array}{c}70-80 \\
80-90 \\
90-100 \\
100-110 \\
>110\end{array}$ & & & & 2 & & & & & Io & & & & & & & & & & & & 12 \\
\hline Total & & & & 23 & & & & & 44 & & & & & 16 & & & & & 3 & & & 86 \\
\hline
\end{tabular}


Boring (Drilling) Percussion drills of various types are used, depending on the locality and the nature of the work to be done. Little effort is required in the operation of the drills. Some physical effort is required, however, during collaring of light rock drills. Erecting drills for vertical boring is hard work. Rigging up long hole percussion drills is probably the heaviest work.

Plate Laying This involves a great deal of moderately hard work with a pick and shovel but two men are usually involved and they take turns at the hard work.

Timbering This is also considered by the men to be hard work.

In general, the work rates were considered by the physiologist to be between light and moderate (i.e., 2.5 and $5 . \circ \mathrm{Cal} . / \mathrm{min}$.) with most jobs in the light category. Since the study was carried out mechanization of the mine has progressed and now many diesel-powered front-end loaders are in use so that even more of the tasks are now in the light work category. Where men work hard (i.e., 7.5 to Io Cal./min.), periods of rest or light work are interspersed. Workmen are supervised for only brief periods by the shiftbosses. They are paid on contract and the physical effort they put into the task depends upon their motivation to earn high wages. When they feel tired, or uncomfortably hot, they generally withdraw to a cool place to rest.

Clothing Almost without exception the men worked in long trousers and shirts. The shirts were either longsleeved or singlets ( $T$-shirts). In hot conditions the shirts were unbuttoned but the men rarely removed them. This is probably due to the fact that the shirts protect the skin from the fine dust which is removed with difficulty when the men shower after the shift. Underground clothing is generally washed only once a week and often becomes caked with dust and also with grease and oil from drilling.

Step-test Underground in Hot Conditions Twenty-nine men volunteered for this study. Seven men volunteered for two periods of exposure. The second was at a different air condition and is therefore treated as a separate observation. The men stepped on and off a stool at a rate of 12 times per minute. The height of the stool was adjusted in relation to the man's weight so that at the particular rate of stepping all the men performed work at a rate of $1,560 \mathrm{ft} .1 \mathrm{~b} . / \mathrm{min}$. The oxygen consumption for this task is very close to $\mathrm{I} \cdot \mathrm{O} 1 \mathrm{l}$ /minute. The equivalent rate of metabolism is 5 Cal./minute. The men worked continuously for three hours, with short breaks at the end of each hour during which measurements of oral temperatures and body weights were made. Heart rates were measured with a stethoscope while the men stepped. Fluid intakes and outputs were also measured accurately so that hourly sweat rates could be calculated. Subjects wore only underpants during this study.

An underground site was selected in which the environment could be changed. The range of dry-bulb temperatures was from $99^{\circ}$ to $116^{\circ} \mathrm{F}$., of the wet-bulb temperatures from $82^{\circ} \mathrm{F}$. to $90^{\circ} \mathrm{F}$., of the globe temperature from $100^{\circ}$ to $121^{\circ} \mathrm{F}$., and of wind velocity from 50 to $\mathrm{I} 80 \mathrm{ft}$. $/ \mathrm{min}$. The range of C.E.T. was from $86 \cdot 8^{\circ}$ to $94.5^{\circ} \mathrm{F}$. and of $\mathrm{P}_{4} \mathrm{SR}$ from $2 \cdot 8$ to 7.7 litres.

The main objects of the stepping study were:

(a) To be able to relate oral temperature to the various heat stress indices on men working at a constant moderate rate of work for three hours and to compare this relationship with that determined from the observations of the men 'on the job'. The two samples of men would be comparable with respect to their states of acclimatization as they were both samples of the ordinary underground workmen. The men who volunteered for the step-test tended to be younger, and a higher percentage were engaged in 'raising', which requires ladder climbing.

(b) To compare the oral and rectal temperatures of men working in heat: It was felt by the mine management, however, that regular rectal temperature measurements might have led to some antagonism on the part of the volunteers, so that this aspect of the study was abandoned.

(c) To estimate the state of acclimatization of the ordinary workmen in the mine by comparing the temperatures measured during these studies with those of unacclimatized and highly acclimatized young Bantu in South Africa over a similar range of heat stress conditions.

\section{Results}

Preliminary Observations A detailed timestudy was made of the environmental conditions and the work rates of six men during the first three hours of their shifts. The men work an 8-hour shift, which is calculated as the time taken from bank to bank. Time taken in travelling to and from the working place and 'crib' (relaxation) time accounts for approximately two hours, so that the actual time in the working places is six hours. About three hours of this are before 'crib' time and three hours after it.

The detailed observations on one of the six men are given in Appendix I (p. 269). There, it will be seen that the men sometimes work hard in very severe heat for short spells, but they usually rest or perform light work in cooler conditions after such bouts of activity in hot conditions.

$\mathrm{P}_{4}$ SRs were calculated for each period of activity. Where the work rate and/or heat stress was too high to calculate the actual $P_{4} S R$ value from the nomogram, then a value of 10.0 was taken. From individual values, average $\mathrm{P}_{4}$ SRs were calculated for each of the first three hours of work and they are given in Table II. This Table also contains the $\mathrm{P}_{4} \mathrm{SR}$ measured at the end of the third hour of work from the single spot observation. From this Table it will be seen that the $\mathrm{P}_{4}$ SRs decrease steadily over the first three hours of the shift. However, the 
TABLE II

Predicted 4-Hour Sweat Rate (litres)

\begin{tabular}{c|c|c|c|c}
\hline $\begin{array}{c}\text { Pay } \\
\text { No. }\end{array}$ & $\begin{array}{c}\text { Average } \\
\text { Ist Hour }\end{array}$ & $\begin{array}{c}\text { Average } \\
\text { 2nd Hour }\end{array}$ & $\begin{array}{c}\text { Average } \\
\text { 3rd Hour }\end{array}$ & $\begin{array}{c}\text { End of } \\
\text { Hour }\end{array}$ \\
\hline 05135 & 5.90 & 5.10 & 3.48 & 3.45 \\
05564 & 5.61 & 4.32 & 4.37 & 4.35 \\
04051 & 6.36 & 6.25 & 5.46 & 5.80 \\
05824 & 5.29 & 5.72 & 4.41 & 4.15 \\
06887 & 4.05 & 4.15 & 3.20 & 3.10 \\
07457 & 4.09 & 4.16 & 3.87 & 3.20 \\
\hline Average & 5.22 & 4.95 & 4.13 & 4.01 \\
\hline
\end{tabular}
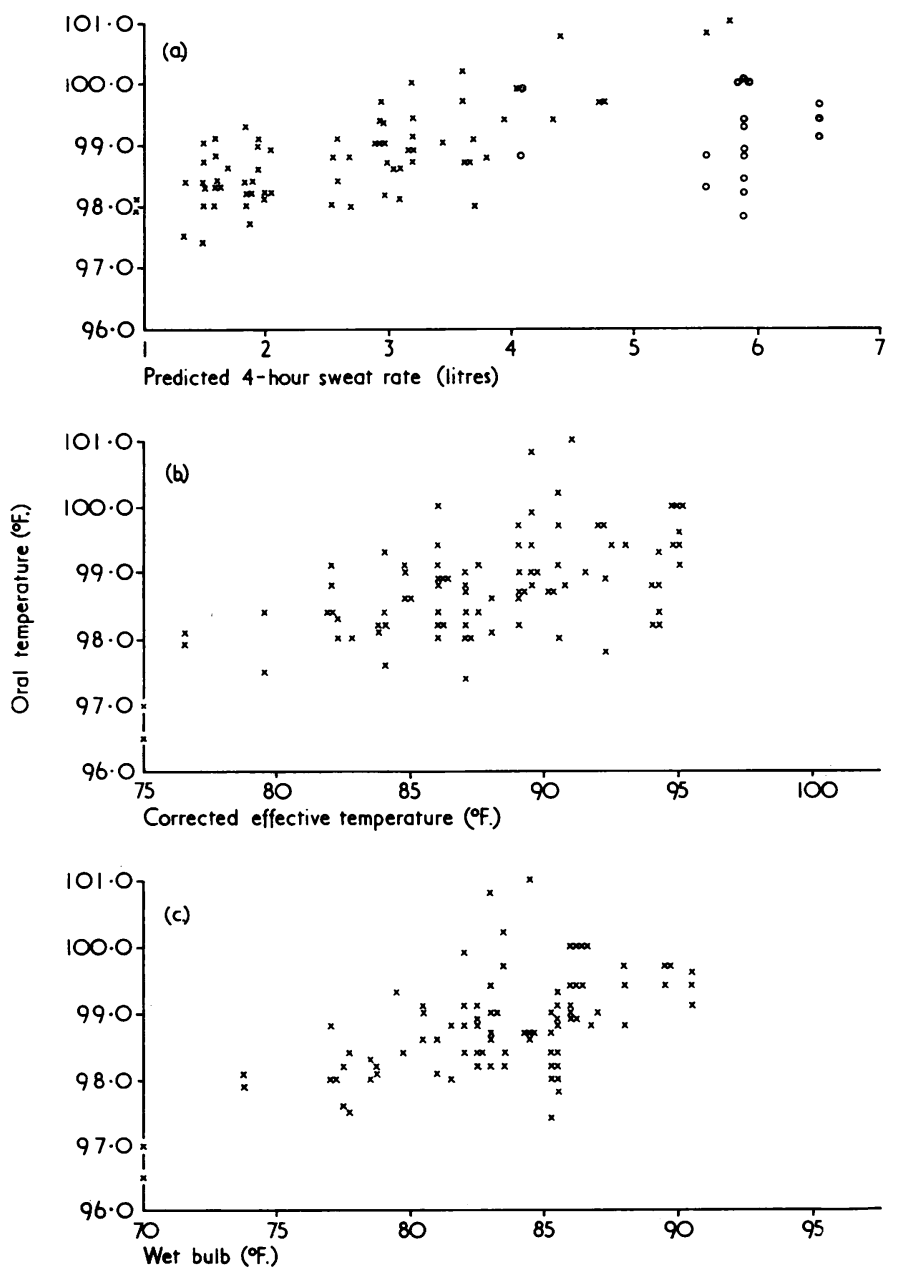

FIG. I. Mount Isa. Men at work.

(a) Oral temperature vs. P,SR; (b) oral temperature vs. corrected effective temperature; (c) oral temperature vs. wet bulb. average $\mathbf{P}_{4} S R$ during the third hour is closely similar to that measured at the end of the third hour.

The second preliminary study was to compare the mean oral temperature of 26 men at the end of the third hour with the mean of the same 26 men at the end of the second hour of work after 'crib' time. Student's ' $t$ ' test showed that the difference of the means was not significant at the $5 \%$ level.

Oral Temperatures, Measured 'on the Job', related to C.E.T. and $P_{4} S R$ In Fig. I (a), (b) and (c) are plotted the oral temperatures, measured on the 86 workmen at the third hour of the shift, against $\mathrm{P}_{4}$ SR, C.E.T., and W.B. The plots of oral temperature in Fig. I (a), where G.T. was more than IO ${ }^{\circ} \mathrm{F}$. higher than D.B., are marked by circles. This shows that these plots form a cluster of points which are different from the plots of oral temperature for other air conditions. These data have, therefore, been omitted in calculating the regression equations of the relationships between oral temperature and the heat stress index values and in calculating correlation coefficients.

Correlation coefficients were calculated for oral temperatures on $\mathrm{P}_{4} \mathrm{SR}$, C.E.T., and W.B. for the 69 observations (the 17 observations where G.T. was more than $10^{\circ} \mathrm{F}$. above D.B. were omitted). The correlation coefficients are:

with $\mathrm{P}_{4} \mathrm{SR}=0.75$

with C.E.T. $=0.64$

with W.B. $=0.5 \mathrm{I}$.

This result shows that the relationship between oral temperature and W.B. is not as close as with either C.E.T. or $P_{4}$ SR. This suggests that in the air conditions underground in the mine at Mount Isa, Haldane's (1905) conclusion that W.B. could be used as the index of heat stress does not hold. All subsequent analyses were, therefore, made with C.E.T. and $\mathrm{P}_{4} S R$ values.

In Fig. 2 oral temperatures have been plotted against $\mathrm{P}_{4} S R$ values.

A regression equation was calculated for the plots of oral temperature against $P_{4} S R$ values for conditions where the difference between D.B. and W.B. was less than $10^{\circ} \mathrm{F}$. and this is:

$$
\mathrm{Y}=0 \cdot 480 \mathrm{X}+97 \cdot 756
$$




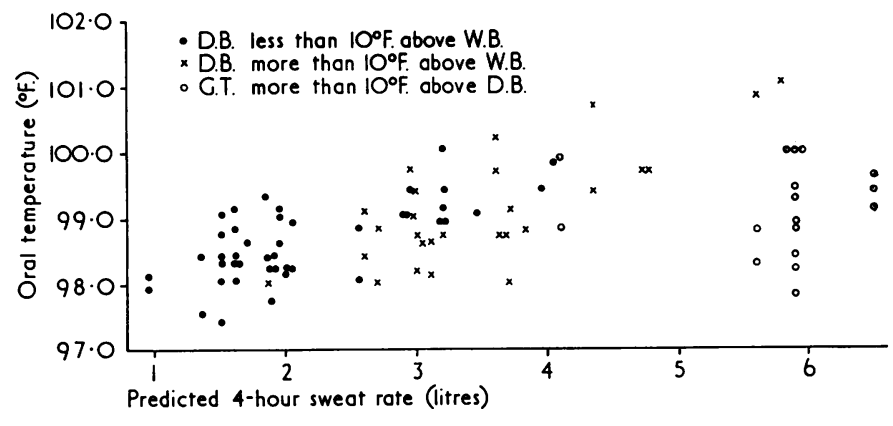

FIG. 2. Mount Isa. Men at work. Oral temperature vs. $\mathbf{P}_{4}$ SR.

where $\mathrm{Y}$ is oral temperature $\left({ }^{\circ} \mathrm{F}\right.$.) minus 90 and $\mathrm{X}$ is the $P_{4} S R$ value. The correlation coefficient squared is $0.6 \mathrm{I}$, which is highly significant.

A regression equation was also calculated for conditions where the differences between D.B. and W.B. were more than $10^{\circ} \mathrm{F}$. and this is:

$$
\mathrm{Y}=0.431 \mathrm{X}+97.538 \text { (ii) }
$$

and the correlation coefficient squared is 0.55 , which is also highly significant.

These two regression equations are very similar and tests were made to see whether they could be combined. A test for parallelism was carried out and this gave an $F$ value of $I I \cdot 7 I I$, which indicated that there was no good reason for believing that these lines are not parallel. An analysis of variance for differences in position and in the regressions was then carried out and neither of the $F$ values was significant, which indicates that a single 'overall' regression equation could be used.

The new regression equation is:

$$
\mathrm{Y}=0.412 \mathrm{X}+97.65 \mathrm{I} \quad \text { (iii) }
$$

and the correlation squared is 0.53 , which is highly significant.

A similar analysis was made of oral temperatures plotted against C.E.T. A regression equation was first calculated for oral temperatures against C.E.T. for conditions where the differences between D.B. and W.B. were more than $10^{\circ} \mathrm{F}$. The regression equation is:

$$
\mathrm{Y}=0.148 \mathrm{X}+94.624 \text { (iv) }
$$

and the correlation squared to 0.46 , which is significant.

A regression equation was also calculated for conditions where the differences between D.B. and W.B. are less than $10^{\circ} \mathrm{F}$. and the regression equation is:

$$
\mathrm{Y}=0.135 \mathrm{X}+95.739 \quad(\mathrm{v})
$$

and the correlation squared is 0.66 , which is highly significant.
A test for parallelism gave an $F$ value of 15.022 , from which it can be assumed that the lines are parallel. However, the analysis of variance gave a value for difference in position which is significant at the $I \%$ level, which indicates that the two regressions for oral temperatures against C.E.T. cannot be combined.

From this analysis it can be concluded that the correlations between oral temperatures and both of the heat stress indices are significant. The $P_{4} S R$ index gives similar regression equations, as regards both slope and position, for conditions where the differences between D.B. and W.B. are greater and less than $10^{\circ} \mathrm{F}$., so that in effect one regression equation can be used for both sets of conditions. This means that the $P_{4} S R$ index takes account accurately of the effects on oral temperatures of workmen of conditions where the relative humidity is very high and also of conditions where it is less high. The regression equations of oral temperatures against C.E.T., for these two sets of air conditions, are not coincident and therefore separate regression equations are required to take account of the effects on oral temperatures of the workmen of very high and less high humidities.

'Stepping' Oral Temperatures related to Heat Stress Index Values Plots of the 36 observations of oral temperature on W.B., C.E.T., and $\mathrm{P}_{4} \mathrm{SR}$ at the end of the third hour of stepping at $1,560 \mathrm{ft} .1 \mathrm{~b} . / \mathrm{min}$. are given in Fig. 3 (a), (b), and (c). In none of the environmental conditions in which the step-tests were carried out was the difference between D.B. and W.B. greater than I0 ${ }^{\circ} \mathrm{F}$., nor was the G.T. more than $10^{\circ} \mathrm{F}$. higher than D.B.

A regression equation has been calculated for oral temperatures on $\mathrm{P}_{4} \mathrm{SR}$ values and is:

$$
\mathrm{Y}=0.506 \mathrm{X}+97.508 \quad \text { (vi) }
$$




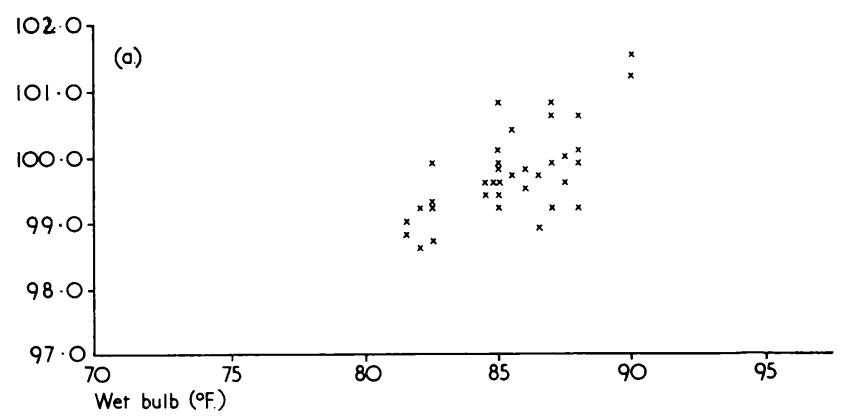

job' (i and ii) and 'stepping' (vi) were similar and it was therefore decided to see whether they could be combined. A test for parallelism gave an $F$ value of $I \cdot 13$, which indicated that there is no good reason for believing that the lines are not parallel, and an analysis of variance gave an $\mathrm{F}$ value for difference of position of $3.6 \mathrm{I}$, which is not significant, so that the equations can be combined. The new 'overall equation' is

$$
\mathrm{Y}=0.478 \mathrm{X}+97 \cdot 524 \text { (viii) }
$$
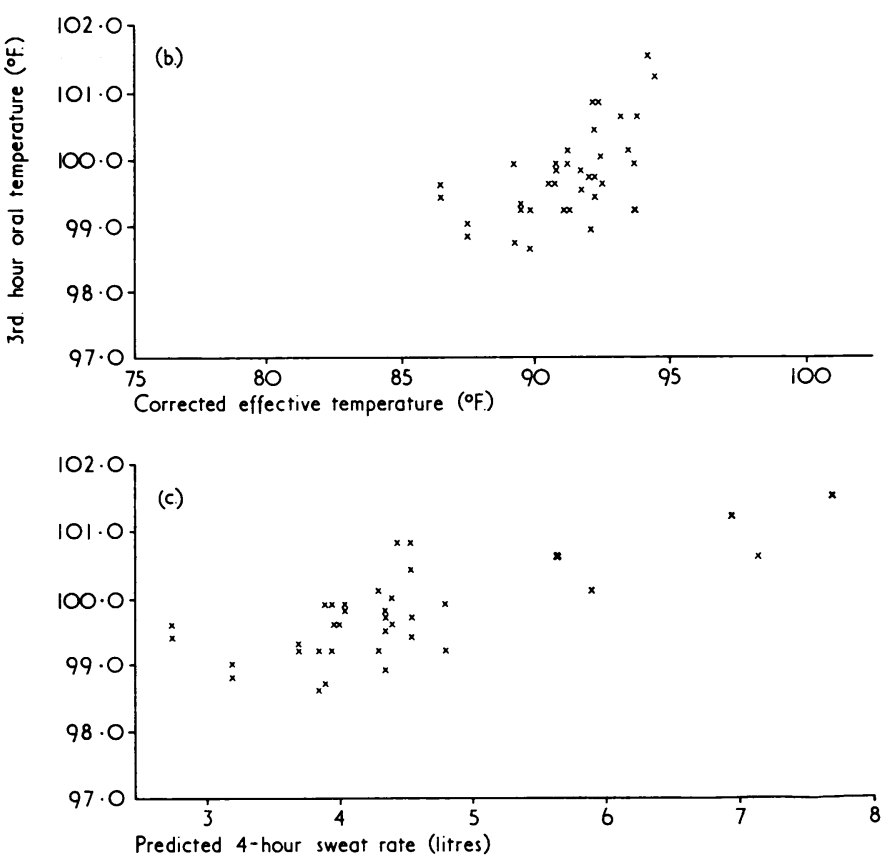

FIG. 3. Mount Isa. Stepping. (a) 3rd hour oral temperature vs. wet bulb;

(b) 3rd hour oral temperature vs. corrected effective temperature;

(c) 3rd hour oral temperature vs. predicted 4 -hour sweat rate.

and the correlation coefficient squared is 0.64 , which is highly significant. Figure 4 contains the plots of oral temperatures of men 'on the job' and 'stepping' and the 'overall' regression line.

The regression equations for oral temperatures against C.E.T. for men 'on the job' and 'stepping' are not coincident. It was reported above that the regression equations for conditions where the differences between D.B. and W.B. were both more and less than $10^{\circ} \mathrm{F}$. could not be combined. Therefore, separate tests had to be carried out for the coincidence of the regression equation for stepping with each of these two regression equations. The tests for parallelism and the variances for differences in position between the group represented in equation (iv) and the stepping group give $F$ values of I.392 and 2.989 respectively, which are not significant so that these two regressions can be combined as follows:

$$
\mathrm{Y}=0 \cdot 128 \mathrm{X}+95 \cdot 776 \text { (ix) }
$$

and the correlation coefficient squared is 0.53 , which is highly significant.

The regression equation for oral temperatures on C.E.T. is:

$\mathrm{Y}=0.209 \mathrm{X}+93.213$ (vii) and the correlation coefficient squared is 0.38 , which is also significant.

Comparisons of 'on the Job' and 'Stepping' Regression Equations The regression equations for oral temperatures on $\mathrm{P}_{4} \mathrm{SR}$ for men 'on the

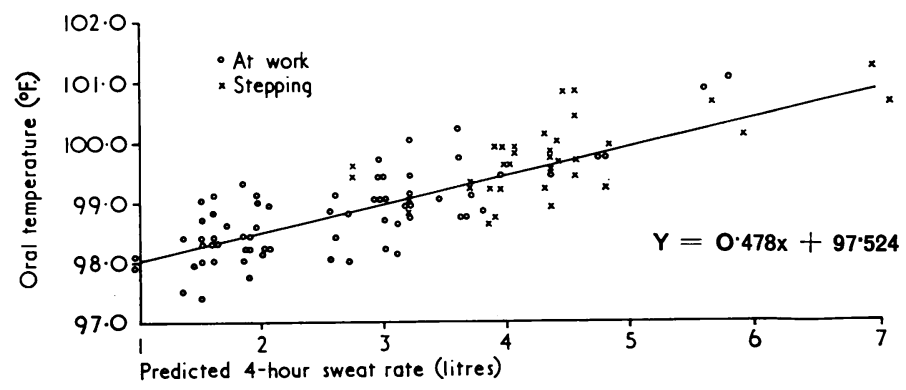

FIG. 4. Mount Isa. Men at work and stepping. Oral temperature vs. P,SR. 
and the correlation coefficient squared is 0.54 , which is highly significant. Similar tests on the group represented in equation (v) and stepping regressions give $F$ values of $I \cdot 309$ and 10.529 ; the latter is significant at the $0.1 \%$ level so that these two regressions cannot be combined.

The main conclusion from this analysis is that the $\mathrm{P}_{4} \mathrm{SR}$ index takes account accurately of all the various environmental conditions and work rates examined at Mount Isa mine (except for conditions where G.T. is more than $10^{\circ} \mathrm{F}$. greater than D.B.), whereas the C.E.T. does not do so. Another is that, because one regression equation can be used for 'stepping' and 'on the job' oral temperatures against $\mathrm{P}_{4} \mathrm{SR}$, the assessment of work rate on the job must be accurate.

State of Acclimatization of the Subjects Studies have been made at the Human Sciences Laboratory in Johannesburg on unacclimatized and highly acclimatized Bantu at the same rate of work and over a similar range of environmental conditions (Wyndham et al., 1966). The state of acclimatization of the workmen underground at Mount Isa mine can be judged by comparing the regression line of oral temperatures on $\mathrm{P}_{4} \mathrm{SR}$ with those of the unacclimatized and highly acclimatized Bantu. These lines are given in Figure 5. From this it is clear that the regression line for the Mount Isa men lies close to that of the highly acclimatized Bantu. From this it can be concluded that after the men have worked for some months underground at Mount Isa mine they are well acclimatized to heat.

\section{Discussion}

Preliminary Observations Detailed observations over the first three hours of the shift of the environmental conditions and of the different physical activities of a subsample of the men 'on the job' showed that these two heat stress factors fluctuate considerably. It would, therefore, be very difficult to simulate in a climatic chamber the underground heat stresses, and a better idea of the heat stresses and the resultant physiological reactions of the workmen can be obtained by making physiological measurements on the workmen while they are carrying out their ordinary tasks.

The oral temperatures measured at the end of the third hour of the shift have not been shown to be significantly different from those measured either during the first two hours or in the afternoon after 'crib' time. It can, therefore, be accepted with some confidence that the oral temperatures measured at the end of the third hour of work are representative of the level of oral temperature throughout the shift.

Oral temperatures were used to assess the men's body temperature reactions to the various heat stress conditions. Differences between oral and rectal temperatures have been reported by Strydom, Morrison, Booyens, and Peter (1956) and by Strydom, Wyndham, Williams, Morrison, Bredell, and Joffe (1965) over a wide range of different heat stress conditions. It can be taken that at the rates of work of the men in this study the rectal temperatures would be about $\mathrm{I} \cdot 0^{\circ} \mathrm{F}$. higher than oral temperatures and that the variations in air temperatures and wind velocities in the mine are not likely to have influenced the differences between these two measurements of body temperature.

Deciding whether C.E.T. or $P_{4} S R$ should be used for predicting Oral Temperatures in the Mine at Mount Isa Macpherson (1962) lists 19 different heat stress indices and even his list is not exhaustive as he omits the Belgian Effective Temperature (Lavenne, 1965). Only the C.E.T. and the $\mathrm{P}_{4} \mathrm{SR}$ indices of heat stress have been examined in this paper because, in our view, they are the only two heat stress indices that have been studied intensively to see whether they give correct weight to the relative physiological effects of the various heat stress parameters.

The results show that the $\mathrm{P}_{4} \mathrm{SR}$ index takes accurate account of air conditions where D.B. is

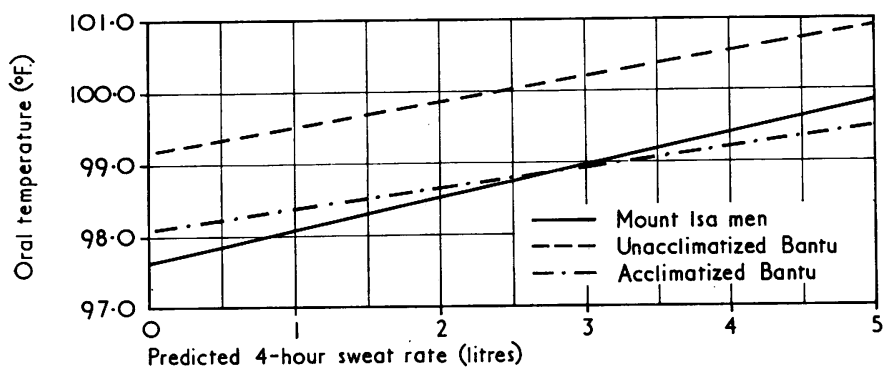

FIG. 5. Regression of oral temperature on P.SR. 
more than $10^{\circ} \mathrm{F}$. above W.B. and also where D.B. is less than $10^{\circ} \mathrm{F}$. above W.B., judged by the similarity of the regressions of oral temperature on $\mathrm{P}_{4} \mathrm{SR}$ for these two sets of conditions. The regression line for 'on the job' observations is not significantly different from that for 'stepping' data. Therefore one regression line can be used in the mine at Mount Isa for all the environmental conditions (except where G.T. is greater than D.B. by more than $10^{\circ} \mathrm{F}$.) and for the different rates of work. This is not the case with C.E.T. Two separate regression lines are required for the two sets of air conditions with different gaps between D.B. and W.B., and the regression line for the 'stepping' data is coincident with only one of these two. Therefore at least two regression lines would be needed for the various environmental and work rate conditions that occur in the mine at Mount Isa. In this very important respect the $\mathrm{P}_{4} \mathrm{SR}$ index has a clear advantage over the C.E.T. scale for predicting oral temperature reactions at different levels of heat stress.

The fact that the regression line for oral temperature on C.E.T. for conditions where D.B. is more than $10^{\circ} \mathrm{F}$. higher than W.B. is significantly higher than the regression line for conditions where D.B. is less than $10^{\circ} \mathrm{F}$. above D.B. supports previous conclusions that C.E.T. exaggerates the influence of high D.B.s (Eichna et al., I945; Robinson et al., 1945). No conclusions can be drawn from the present data on another criticism of C.E.T., namely that it does not give sufficient weight to the improvement in physiological strain from an increase in W.V., at low W.V.s in high W.B.s (Dunham et al., 1946).

It might be objected that the lower correlation coefficient of oral temperature with C.E.T. than with $\mathrm{P}_{4} \mathrm{SR}$ might be due to the fact that no attempt was made in the analyses to separate the oral temperatures into different work rate categories. Smith (1955) has shown that separate regression equations for body temperature against C.E.T. are required for different rates of work. However, this does not appear to be the reason for the low correlation coefficient between oral temperatures and C.E.T. because relatively few of the 86 men were classified as working at a moderate rate and, furthermore, in the experiment in which the 29 men all worked at a work rate of I,560 ft.lb./min., the correlation coefficients showed the same trend (that with $\mathrm{P}_{4} \mathrm{SR}$ was 0.53 and that with C.E.T., 0.38 ).

In conditions where the temperature of the surrounding surfaces is higher than that of the air, Bedford (1946) proposed that the physiological effects of long-wave radiation on man could be taken account of by means of the measurement of the temperature inside a 6-in. blackened copper sphere (G.T.). In determining heat stress index values from the C.E.T. and $\mathrm{P}_{4} S R$ nomograms, G.T. is substituted for D.B. The results of the present study have shown that where G.T. was more than $10^{\circ} \mathrm{F}$. higher than D.B., the $\mathrm{P}_{4} \mathrm{SR}$ values were high and the oral temperatures of the group of subjects under these conditions fell well below the regression lines fitted to the rest of the data. However, if D.B. is used instead of G.T. in working out $P_{4} S R$ values for these conditions, then the plots for this group of subjects fall close to the regression line fitted to the rest of the data. From this evidence it can be concluded that when G.T. is more than $10^{\circ} \mathrm{F}$. higher than D.B., the use of G.T. in calculating $\mathrm{P}_{4} \mathrm{SR}$ from the nomogram exaggerates the physiological effects of the radiant heat load.

There is support for this conclusion with regard to the effect of radiant heat in a multi-variance analysis carried out by one of us (R.A.) to determine the relative effect on $\mathrm{P}_{4} \mathrm{SR}$ values of a one-unit change in D.B., W.B., G.T., W.V., and metabolic rate (the mathematical analysis and the detailed conclusions are given in Appendix 2.) The relationships between these variables are not linear and the following estimates apply to the middle of the ranges of conditions investigated. These are $M=125$, G.T. $=106$, D.B. $=100$, W.B. $=84$, and W.V. $=$ 200.

The results of this investigation are summarized below:

$$
\text { A unit change in }
$$

\begin{tabular}{lc} 
Metabolic rate $\left(\mathrm{Cal} . / \mathrm{m} .{ }^{2} / \mathrm{hr}.\right)$ & the $\mathrm{P}_{4} \mathrm{SR}$ of \\
Globe temperature $\left({ }^{\circ} \mathrm{F}.\right)$ & 0.02 \\
Dry bulb temperature $\left({ }^{\circ} \mathrm{F}.\right)$ & 0.17 \\
Wind velocity $(\mathrm{ft} . / \mathrm{min})$. & -0.09 \\
Wet bulb temperature $\left({ }^{\circ} \mathrm{F}.\right)$ & -0.002 \\
\hline
\end{tabular}

From this analysis it is seen that the W.B. has the greatest effect on $\mathrm{P}_{4} \mathrm{SR}$ and is followed closely by G.T.

The results of this analysis are at variance with the conclusions reached in the Medical Research Council report issued in February 1954 on this subject (Ferris, Fox, Jack, John, Lind, Macpherson, and Newling, 1954), which reads:

'Although no absolute value can be assigned to the effects of increasing the mean radiant temperature the experiments of the two series taken together show that, as measured by the amount of sweat loss per kilogram of body weight, increasing the mean radiant temperature $30^{\circ} \mathrm{F}$. above air temperature (as measured by G.T.), at an air temperature of $100^{\circ} \mathrm{F}$., produces approximately 
the same increase in strain as increasing the air temperature by $10^{\circ} \mathrm{F}$. to $110^{\circ} \mathrm{F}$.'

This statement means that the same effect on $P_{4} S R$ values is seen from a $I^{\circ} F$. change in D.B. and a $30^{\circ} \mathrm{F}$. change in G.T.

The discrepancy between this conclusion and the weighting given to the G.T. in the calculation of the $P_{4} S R$ values does not seem to have been realized, because in the Medical Research Council's Special Report No. 298 on the Singapore experiments, Macpherson (1960) states:

'It was found that the $\mathrm{P}_{4} \mathrm{SR}$ nomogram predicts the sweat loss of fit, acclimatized men in hot conditions in which the mean radiant temperature is above air temperature as accurately as it predicts the sweat loss in those environments in which the mean radiant temperature is equal to the air temperature.'

It appears from this discussion that the method of calculating $\mathrm{P}_{4} \mathrm{SR}$ values from the nomogram needs to be revised for conditions where the G.T. is higher than D.B. The revision should be in the direction of reducing the present weighting given to the effect of the G.T. Instead of its effect being roughly equal to that of the W.B., as it is at present in the nomogram, it appears that its effect should be only one-third as great as D.B., in the particular range of conditions examined.

Comparison of Mount Isa Mine, Queens Square and Singapore Regression Equations for Body Temperature on $P_{4} S R$ It is of interest to compare the regression equations for rectal temperature on $\mathrm{P}_{4} \mathrm{SR}$ from Queens Square and Singapore data with that for oral temperature on $\mathrm{P}_{4}$ SR from the mine at Mount Isa. The Mount Isa mine regression line would be expected to lie at least $\mathrm{I} \cdot 0^{\circ} \mathrm{F}$. below those from Queens Square and Singapore because, according to the findings of Strydom et al. (1965), rectal temperatures, for the rates of work in these three studies, would be approximately $\mathrm{I} \cdot 0^{\circ} \mathrm{F}$. higher than oral temperatures. The three regression lines are compared in Fig. 6 where it is seen that the Singapore and Mount Isa mine regression lines are very nearly parallel and about $\mathrm{I} \cdot 0^{\circ} \mathrm{F}$. apart. The gap between these two lines could be accounted for entirely by the differences between rectal and oral temperature.

The close identity between the Singapore and Mount Isa mine regression lines (when the differences between oral and rectal temperature are taken into account) indicates that the workmen underground at Mount Isa mine are probably as well acclimatized to heat as the subjects in the Singapore studies. This is in accord with the comparison between the workmen at Mount Isa mine and the unacclimatized and highly acclimatized Bantu miners given in the results which indicates that the Mount Isa men were very highly acclimatized to heat.

Deciding upon the Method to be used for determining the Limits of Heat Stress in the Mine at Mount Isa Possibly the most satisfactory way in which the upper limits of heat stress can be determined is by means of an epidemiological study of the type carried out by Wyndham (1956b) in the gold mines of South Africa. Over the five-year period, 1956 to $196 \mathrm{I}$, estimates were made of the number of miners working in different classintervals of W.B. underground, and the numbers were obtained of heat stroke cases occurring at these W.B.s. From these two figures it was then possible to calculate the incidence, in cases per thousand miners per annum, for the various classintervals of W.B. temperature. Curves were fitted to the plots of incidence against W.B. temperature for fatal and non-fatal cases of heat stroke, and confidence limits were calculated to the curves. From these curves it is possible to ste that the probability of heat stroke in South African gold mines is negligible below $82^{\circ} \mathrm{F}$. W.B. The estimate of the probability of heat stroke at $86^{\circ} \mathrm{F}$. W.B. is
FIG. 6. 'Queens Square', 'Singapore' and Mount Isa. Regressions of body temperature on $\mathrm{P}_{4} S R$.

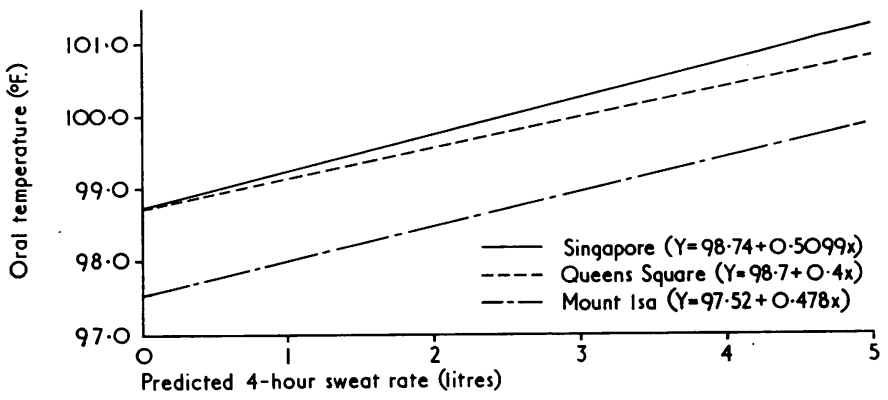


0.33 case per thousand per annum and of fatal cases 0.08 per thousand per annum. At $92^{\circ} \mathrm{F}$. W.B. the risks rise to 2.17 cases per thousand per annum and to 0.57 per thousand per annum for fatal cases of heat stroke. By this means, mine managers in the South African gold mines have been given the risks of heat stroke cases at the various W.B. temperatures, underground, in the mines in the same precise terms as they are accustomed to dealing with in accident and sickness statistics. The mine managers are now in a position to decide upon the risk which they are prepared to accept in their mines and to translate these risks into limits of heat stress. These figures would, of course, not apply in the mine at Mount Isa where the circumstances are different because, first, the work is very highly mechanized and men do not work for long periods at a moderate rate, as is the case in the gold mines in South Africa, and, secondly, the miners do not work under the direct and constant supervision of 'bossboys'.

The above method of determining heat stress limits cannot be used where there is either no incidence of heat stroke or other forms of heat illness, or the incidence is too low for a proper statistical analysis of the results to be made. In these circumstances the approach has been to expose a sample of men to a range of heat stress conditions and to decide upon a criterion for judging when the subjects of the experiment have reached the limit of heat stress. For example, Eichna et al. (1945), at the Fort Knox Laboratory in U.S.A., judged the limits of heat stress for a moderate rate of work as:

'(conditions) which rapidly led to total disability in most men, with excessive, often disturbing, physiologic changes'.

The physiologists of the British Medical Research Council engaged upon similar studies gave in 1947 (Macpherson, 1960) their definition for the limit of heat stress as:

'a situation in which an increasing number of fit, acclimatized men found conditions beyond their endurance'.

It is clear that the criterion used by both these groups of research physiologists for judging the limit of heat stress is heat collapse and/or acute heat fatigue. Based upon these criteria, the Fort Knox Laboratory found that young, fit, highly acclimatized and well motivated men were able to complete four hours of continuous work at a moderate rate (about $5 \mathrm{Cal} . / \mathrm{min}$.) at a C.E.T. of $92^{\circ} \mathrm{F}$., though the men experienced some difficulty in doing so. Wyndham, Bouwer, Devine, and Patterson's (1953) findings on highly acclimatized Bantu miners were similar. The limiting C.E.T. in the British studies for a lower rate of work was $90^{\circ} \mathrm{F}$. (Weiner and Lind, 1955).

It can be objected that a limit of heat stress which is based upon heat collapse and/or acute heat fatigue is too arduous for miners who will be exposed to such heat every day of their working lives. With this point in mind, physiologists have looked for an alternative. Some physiological criterion (or criteria) is needed which gives a clear indication that the degree of strain, i.e., the departure from normality, of the main temperature regulatory mechanisms is considerable but is not so severe that heat collapse, or any other form of heat illness, can be expected to occur. Wyndham et al. in 1953 attempted to meet this requirement by extending Nielsen's classic 1938 observations. Nielsen had shown that, when a man works, his rectal temperature rises to a new steady level in about 40 to 60 minutes and remains at that level for as long as the work continues. The new level is directly proportional to the rate of metabolism over a wide range of air temperatures. Wyndham et al. (1953) demonstrated that Nielsen's observations are only true up to certain critical levels of heat stress. When men work in heat stress which is above the critical level then their rectal temperatures rise to new, higher levels and there are indications that their temperature regulatory mechanisms are no longer able to cope fully with the total heat load imposed upon them. It was also observed that the higher the rate of metabolism the lower was the critical level of heat stress.

Applying these concepts to 13 highly acclimatized Bantu miners who worked for four hours in a climatic room, Wyndham and his colleagues (1953) showed that the 'average' acclimatized Bantu in the South African gold mines was able to maintain his rectal temperature at the steady level, appropriate for the rate of work, up to a C.E.T. of $89^{\circ} \mathrm{F}$. for light work, up to $86^{\circ} \mathrm{F}$. for moderate work, and up to $83^{\circ} \mathrm{F}$. for hard work. Using exactly the same criterion, Lind in 1960, on a sample of three men exposed for one hour, stated that the 'average' British coal miner can maintain a steady level of rectal temperature in C.E.T.s up to $86.4^{\circ} \mathrm{F}$. for light work, up to $8 \mathrm{r} \cdot 3^{\circ} \mathrm{F}$. for moderate work, and up to $80.4^{\circ} \mathrm{F}$. for hard work.

On the basis of their results, Wyndham and his colleagues (1953) recommended to the gold mining industry in South Africa that it would be safe for acclimatized Bantu men to work underground in mines at a moderate rate in C.E.T.s up to $86^{\circ} \mathrm{F}$. This limit proved to be too optimistic because in the period 1956 to $196 \mathrm{I}$, during which the 
Laboratory kept a careful record of all heat stroke cases (Wyndham, 1965b), there were a number of heat stroke cases in C.E.T.s below $86^{\circ} \mathrm{F}$. The reasons for underestimating the risks of heat stroke at C.E.T.s below $86^{\circ} \mathrm{F}$., on the basis of the above experimental results, has since become clear. The Laboratory has found that, whenever large numbers of ordinary Bantu miners are studied under heat stress conditions, a small proportion always show much higher rectal temperatures than the 'average'. This finding is expressed in another way in the skewness to the right, and more dangerous rectal temperatures, that develops in the distribution of body temperatures after about three hours of physical work in heat (Winer, Maritz, and Wyndham, 1962). The reasons for the relative heat intolerance of these particular men has not yet been fully elucidated but the Bantu miners, probably as all workmen, vary in respect to factors which are known to affect the state of acclimatization to heat. These are the men's physical fitness; age; nutrition; their habits with respect to sleep, food, and water and alcohol intake; the presence of chronic diseases such as bronchitis; the susceptibility to upper respiratory viruses, etc. That the ordinary run-ofmill population is not as heat-tolerant as experimental subjects in hot room studies appears also to have been accepted by Weiner and Lind (1955) in their statement, ' $j$ t was, of course, recognized that all men serving in the Navy were not as fit or as young as the subjects who took part in the experiments ... and an E.T. of $86^{\circ} \mathrm{F}$. would be safer in practice (our italics) as the upper limit to which men could reasonably be exposed daily'.

Heat stroke limits, such as those proposed by Wyndham and his colleagues in 1953 and by Lind in 1960, which do not take account of the variability between individuals in their reactions to heat, are bound to fail, as happened in the case of Wyndham et al.'s (1953) recommendations based upon 13 highly acclimatized and very fit Bantu miners.

In an endeavour to meet the above objections, Wyndham and his co-workers in 1965 proposed a new physiological criterion for judging the limits of heat stress and also a new procedure for determining the limits in industrial situations. The present study is an application of these proposals. The new physiological criterion is based upon the response characteristic of the curve, expressing the control of sweat rate by the temperature of the core of the body (measured as rectal temperature), one of the body's main temperature regulating mechanisms (Wyndham, 1965a). The characteristic curve expressing this relationship has a sigmoid shape. Over the range of rectal temperatures between $99 \cdot 5$ and $10 \mathrm{I} \cdot 5^{\circ} \mathrm{F}$. (i.e., oral temperatures between 98.5 and $100.5^{\circ} \mathrm{F}$.), the increase in rate of sweating with rise in rectal temperature is rapid, i.e., the control is at its most 'sensitive'. Once the rectal temperature exceeds $102 \cdot 5^{\circ} \mathrm{F}$., there is no increase in the rate of sweating, i.e., the control channel is 'saturated'. Further increase in heat stress, either in the rate of metabolism or in environmental heat, is liable to result in a rapid rise in rectal temperature and, if exposure to heat is continued, rectal temperature may reach heat stroke levels. On the basis of these concepts, Wyndham and his colleagues in 1965 proposed that work in heat can be regarded as 'easy' when the workmen's rectal temperatures do not rise above IOI $\cdot 5^{\circ} \mathrm{F}$. (oral temperature of $100.5^{\circ} \mathrm{F}$.) and that when rectal temperatures rise above $102.5^{\circ} \mathrm{F}$. (oral temperature of IOI $\cdot 5^{\circ} \mathrm{F}$.) the heat stress can be regarded as 'excessive'.

Determining the Upper Limits of Heat Stress for Work in the Mine at Mount Isa One of the main objects of these studies was to provide the management of the mine at Mount Isa with the limits of heat stress for work in the mine at which (I) the shift should be shortened-the 'six-hour' limit; and (2) the work should be stopped-the 'stop-work' limit.

Translated into Mount Isa mine's '6-hour' and 'stop-work' limits, it is proposed that, on the basis of the above discussion, an oral temperature of $100.5^{\circ} \mathrm{F}$. be the physiological limit for the ' 6 -hour' shift and an oral temperature of IOI $.5^{\circ} \mathrm{F}$. be the limit for 'stop-work'.

A decision had then to be reached on the levels of probability which would be acceptable to both the mine management and the trade unions concerned of workmen reaching these two physiological limits of oral temperature. It was proposed that the limit of heat stress for the 6-hour shift should be one at which there would be a probability of only I : 100 men reaching an oral temperature of $100.5^{\circ} \mathrm{F}$. This means that very few, if any, men working in heat stress below this limit would experience any difficulty due to heat in completing the shift. For the 'stop-work' limit it was decided to keep very low the probability of men reaching an oral temperature of $101 \cdot 5^{\circ} \mathrm{F}$. because, if men work with oral temperatures in excess of this level, they might suffer from heat collapse and/or acute heat fatigue. The 'stop-work' limit was based, therefore, upon a probability of only $I: 2,000$ men reaching an oral temperature of $\mathrm{IOI} \cdot 5^{\circ} \mathrm{F}$. This level of probability appeared to be reasonable and to be fair to both mine management and the trade unions. 


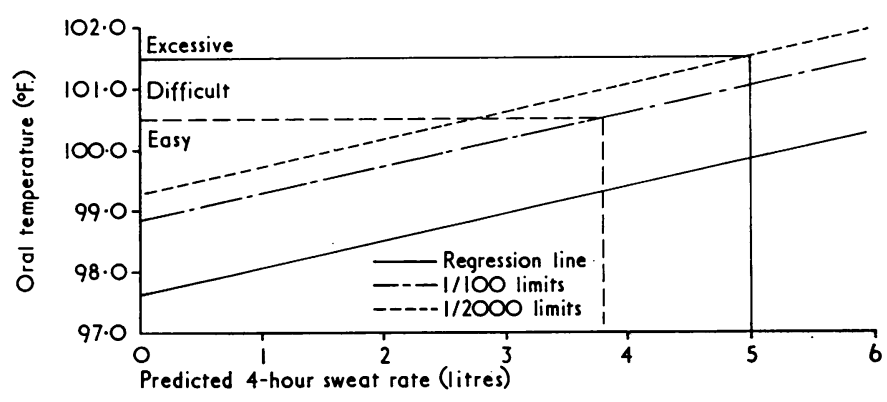

FIG. 7. Oral temperature vs. P\&SR with $I$ in 100 and $I$ in 2,000 limits (see text).

The next step in arriving at these two limits of heat stress was to calculate $I: I 00$ and $I: 2,000$ probability limits to the overall regression line of oral temperature on $\mathrm{P}_{4} \mathrm{SR}$ from Figure 4. These limits are given in Figure 7. It will be seen from this Figure that the $I$ : I00 probability limit cuts the $100.5^{\circ} \mathrm{F}$. oral temperature line at a $\mathrm{P}_{4} \mathrm{SR}$ value of 3.8 and the $I: 2,000$ probability limit cuts the oral temperature line of $101 \cdot 5^{\circ} \mathrm{F}$. at a $\mathrm{P}_{4} \mathrm{SR}$ value of 5.0 . The heat stress limit for a 6-hour shift is, therefore, a $\mathrm{P}_{4} \mathrm{SR}$ of 3.8 and the limit for 'stop-work' is a $\mathrm{P}_{4}$ SR of $5 \cdot 0$.

The Application of the Heat Stress Limits in the Mine at Mount Isa In order to apply the above heat stress limits in the mine, $\mathrm{P}_{4} \mathrm{SR}$ values have to be determined underground. For this purpose measurements are needed of D.B., W.B., G.T., and W.V. and an assessment of work rate. Apart from the measurement of G.T., all these measurements are part of the routine measurements made by the ventilation officers in the mine. Estimates of work rates into the categories of light, moderate, and hard present no difficulty because mining operations in the mine at Mount Isa are highly mechanized and few jobs fall into the category of moderate work. Hard work is rarely done and when it occurs it is of short duration.

There are two difficulties in making the assessment of $\mathrm{P}_{4} \mathrm{SR}$ values in working places. One is the measurement of G.T. The method in general use is the measurement of the temperature at the centre of a blackened, 6-in. copper sphere (Bedford, 1946). However, the time response of the globe is very slow and it may take 20 to 30 minutes before the temperature reaches a steady level. This is a serious handicap in a mine because the ventilation officer is expected to cover a large area of the mine when he makes a survey of the air conditions in working places underground. It was, therefore, decided to see whether it would be possible to replace the G.T. with a measurement of temperature by means of a mercury thermometer with a blackened bulb. Forty pairs of measurements with these two instruments were made over the range of air conditions that occur underground in the mine at Mount Isa. Analysis of the data shows that there is no bias between the two measurements and from the confidence limits fitted to the regression line of blackened thermometer temperature on G.T. it can be stated that only $\mathrm{I}: 20$ temperatures measured by the blackened thermometer would differ from the G.T. by more than $3.0^{\circ} \mathrm{F}$. The results of these studies have shown that the physiological effects of long-wave radiation in the mine at Mount Isa are less than those of either W.B. or D.B. As a rough yardstick it can be taken that the physiological effect of a one-degree Fahrenheit change in G.T. is about one-third the effect of a similar change in D.B. and about one-fifth the effect of a similar change in W.B. in the range of air conditions in the mine at Mount Isa. A relatively crude method of measuring mean radiant temperature, such as that proposed, is therefore acceptable.

The other difficulty is the method of estimating $\mathrm{P}_{4}$ SR values from the nomogram and the associated procedures given in the 1947 report on the subject (Macpherson, 1960). These are unnecessarily complicated and too difficult to be used by underground officials in making 'on the spot' decisions as to whether a 6-hour or a 'stop-work' limit of heat stress has been reached. A simplified procedure has, therefore, been worked out for use in the mine at Mount Isa and is being tried underground. The first step was to decide upon a single rate of work upon which all subsequent calculations of $P_{4} S R$ would be made. In the light of experience of the rates of work in the mine at Mount Isa a rate of metabolism of $125 \mathrm{Cal} . / \mathrm{m}^{2} / \mathrm{hr}$. (approximately $3 \cdot 8$ $\mathrm{Cal} . / \mathrm{min}$.) was chosen because it is about midway between light and moderate work. Next, two rates of W.V. were chosen, 50 and $200 \mathrm{ft}$./min., as they cover most of the range of air movements in working places. The third step was to estimate from the 
$\mathrm{P}_{4} \mathrm{SR}$ nomogram, for the above rate of work and the two W.V.s, the various combinations of D.B.s, in the range $80^{\circ} \mathrm{F}$. to $130^{\circ} \mathrm{F}$., and the W.B.s, in the range $80^{\circ} \mathrm{F}$. to $94^{\circ} \mathrm{F}$., which would give, first, a $\mathrm{P}_{4}$ SR of 3.8 and, second, a $\mathrm{P}_{4}$ SR of 5.0 . Two graphs were then drawn up with D.B. on the abscissa and W.B. on the ordinate. In the '6-hour' graph, the various combinations of D.B. and W.B. which give a $\mathrm{P}_{4} \mathrm{SR}$ of 3.8 were plotted for $50 \mathrm{ft}$. $/ \mathrm{min}$. and for $200 \mathrm{ft}$. $/ \mathrm{min}$. Smooth curves were fitted to these plots. A similar procedure was followed for the 'stop-work' limit graph. These are given in Figs. 8 and 9 respectively.

The effect of radiant heat is taken into account by adding $I^{\circ} \mathrm{F}$. to the measured D.B. for every $3^{\circ} \mathrm{F}$. difference between the temperature of the thermometer with a blackened bulb, after it has been exposed for ro minutes. This correction for radiant heat is not strictly correct because the relative effect on physiological reactions of a unit difference between D.B. and W.B. is not uniform over the range of G.T.s and D.B.s that occur in the mine at Mount Isa. However, owing to the relatively small influence of G.T. compared with the effect of W.B. in this range of air conditions, the errors introduced by this simplifying procedure are not likely to be large.

In practice, the ventilation officer first makes his measurements of D.B. and W.B. by means of a whirling hygrometer, of G.T. with a thermometer with a blackened bulb, and W.V. by means of a hot wire anemometer or by means of a smoke test. If the G.T. exceeds the D.B. he calculates the correction he must make to the D.B. (i.e., $\mathrm{I}^{\circ} \mathrm{F}$. for every $3^{\circ} \mathrm{F}$. difference between G.T. and D.B.). On the $\mathrm{P}_{4}$ SR graph for $3 \cdot 8$, he then locates the measured W.B. and the corrected D.B. He notes whether the intercept of these two temperatures falls above or below the curve for the appropriate W.V. If the intercept falls below the curve, then the heat stress of the work situation does not call for any action. If it falls above, he then follows the same procedure with the graph for a $P_{4} S R$ of 5.0 and notes whether the intercept of the temperature lines falls above or below the curve for the appropriate wind velocity. If it falls below, then the heat stress of the conditions is such that the shift should be limited to six hours. If the intercept falls above the curve then the 'stop-work' limit is invoked and the men are withdrawn from the working area.
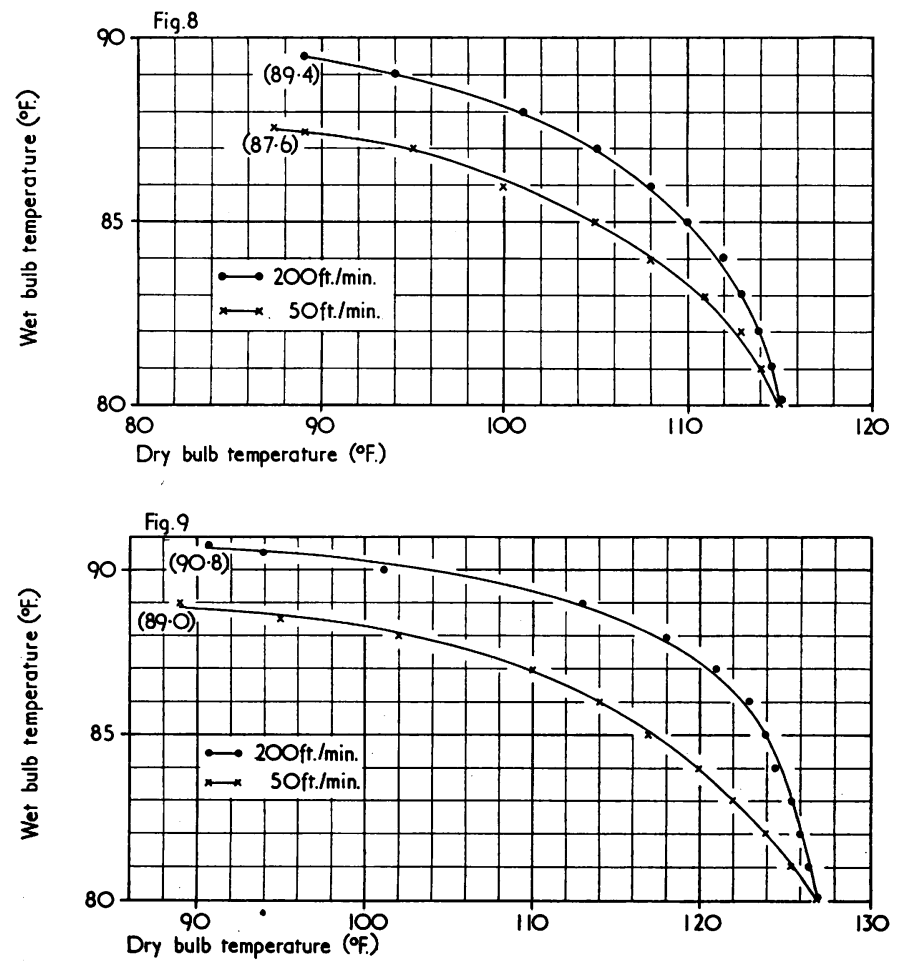

FIG. 8. Curves for P,SR of 3.8: 6-hour limit (for wind velocities of 50 and $200 \mathrm{ft} / \mathrm{min}$.)

FIG. 9. Curves for PASR of 5.0: stop-work limit (for wind velocities of 50 and $200 \mathrm{ft} / \mathrm{min}$.) 


\section{APPENDIX I}

Pay No. 05135

Age 22 years

Working place $\mathrm{X}_{55 / 56}$ Stope 5 SVB
Experience in heat More than one month in hot area

Clothing Short-sleeve singlet and long trousers

Nationality Australian

\begin{tabular}{|c|c|c|c|c|c|c|c|c|c|}
\hline Time & $\begin{array}{c}\text { Duration } \\
\text { (min.) }\end{array}$ & $\begin{array}{l}W . B . \\
\left({ }^{\circ} F .\right)\end{array}$ & $\begin{array}{l}\text { D.B. } \\
\left({ }^{\circ} \mathrm{F} .\right)\end{array}$ & $\begin{array}{l}\text { G.T. } \\
\left({ }^{\circ} F .\right)\end{array}$ & $\begin{array}{c}\text { W.V. } \\
(\text { ft. } / \text { min. })\end{array}$ & Activity & $\begin{array}{l}\text { Work } \\
\text { Rate }\end{array}$ & $\begin{array}{c}\text { Oral } \\
\text { Temp. }\left({ }^{\circ} F .\right)\end{array}$ & $\begin{array}{l}P, S R \\
\text { (litres) }\end{array}$ \\
\hline $\begin{array}{c}0.00-0.05 \\
0.05-0.18 \\
0.18-0.24 \\
0.24-0.30 \\
0.30-0.32 \\
0.32-0.37 \\
0.37-0.39 \\
0.39-0.44 \\
0.44-0.47 \\
0.47-0.49 \\
0.49-0.51 \\
0.51-0.59 \\
0.59-1.00 \\
\text { End of Ist hou }\end{array}$ & $\begin{array}{r}5 \\
13 \\
6 \\
6 \\
2 \\
5 \\
2 \\
5 \\
3 \\
2 \\
2 \\
8 \\
1\end{array}$ & $\begin{array}{r}91 \cdot 5 \\
84 \cdot 0 \\
105 \cdot 0 \\
85 \cdot 0 \\
85 \cdot 0 \\
85 \cdot 0 \\
107 \cdot 0 \\
90 \cdot 5 \\
90 \cdot 5 \\
102 \cdot 0 \\
87 \cdot 0 \\
85 \cdot 0 \\
87 \cdot 0\end{array}$ & $\begin{array}{l}125 \cdot 5 \\
112 \cdot 0 \\
120 \cdot 0 \\
114 \cdot 0 \\
114 \cdot 0 \\
114 \cdot 0 \\
124 \cdot 0 \\
116 \cdot 0 \\
116 \cdot 0 \\
125 \cdot 0 \\
116 \cdot 0 \\
114 \cdot 0 \\
116 \cdot 0\end{array}$ & $\begin{array}{r} \pm 130 \\
113 \\
\pm 130 \\
114 \\
114 \\
114 \\
\pm 132 \\
\pm 120 \\
\pm 120 \\
\pm 132 \\
\pm 116 \\
114 \\
\pm 116\end{array}$ & $\begin{array}{r} \pm 30 \\
300 \\
\pm 30 \\
300 \\
300 \\
300 \\
\pm 30 \\
\pm 150 \\
\pm 150 \\
\pm 30 \\
\pm 30 \\
300 \\
\pm 30\end{array}$ & $\begin{array}{l}\text { Walking, preparing tackle for scraper } \\
\text { Working scraper motor } \\
\text { Walking, fixing ventpipe, etc. } \\
\text { Working scraper motor } \\
\text { Drinking water } \\
\text { Working scraper motor } \\
\text { Walking } \\
\text { Mucking with shovel } \\
\text { Sitting } \\
\text { Walking } \\
\text { Fixing scraper } \\
\text { Working scraper motor } \\
\text { Fixing rope }\end{array}$ & $\begin{array}{l}M \\
\text { L } \\
M \\
\text { L } \\
\text { S } \\
\text { L } \\
M \\
M \\
\text { S } \\
\text { M } \\
\text { S-L } \\
\text { L }\end{array}$ & $99 \cdot 6$ & $\begin{array}{r} \pm 10.00 \\
3.45 \\
10.00 \\
3.65 \\
2.70 \\
3.65 \\
10.00 \\
10.00 \\
3.95 \\
10.00 \\
4.05 \\
3.65\end{array}$ \\
\hline $\begin{array}{l}1 \cdot 00-1 \cdot 02 \\
1 \cdot 02-1 \cdot 07 \\
1 \cdot 07-1 \cdot 13 \\
1 \cdot 13-1 \cdot 30 \\
1 \cdot 30-1 \cdot 32 \\
1 \cdot 32-1 \cdot 33 \\
1 \cdot 33-1 \cdot 42 \\
1 \cdot 42-1 \cdot 48 \\
1 \cdot 48-1 \cdot 59 \\
\text { End of } 2 \text { nd ho }\end{array}$ & $\begin{array}{r}2 \\
5 \\
6 \\
17 \\
2 \\
1 \\
9 \\
6 \\
\text { II }\end{array}$ & $\begin{array}{r}85 \cdot 0 \\
108 \cdot 0 \\
85 \cdot 0 \\
86 \cdot 0 \\
100 \cdot 0 \\
85 \cdot 0 \\
99 \cdot 0 \\
85 \cdot 0 \\
83 \cdot 0\end{array}$ & $\begin{array}{l}\text { II } 4 \cdot 0 \\
119 \cdot 0 \\
114 \cdot 0 \\
114 \cdot 0 \\
126 \cdot 0 \\
114 \cdot 0 \\
125 \cdot 0 \\
114 \cdot 0 \\
109 \cdot 0\end{array}$ & $\begin{array}{r}\text { I } 44 \\
\text { I25 } \\
\text { I14 } \\
\text { I14 } \\
\text { I30 } \\
\text { II4 } \\
\pm \text { I30 } \\
\text { I1 } 4 \\
\text { II3 }\end{array}$ & $\begin{array}{r}300 \\
\pm 30 \\
300 \\
100 \\
\pm 30 \\
300 \\
\pm 30 \\
300 \\
\pm 300\end{array}$ & $\begin{array}{l}\text { Working scraper motor } \\
\text { Change blocks for scraper } \\
\text { Standing to cool off } \\
\text { Working at motor } \\
\text { Fixing rope, etc. } \\
\text { Working at machine } \\
\text { Fixing rope, using Io lb. hammer } \\
\text { Standing, etc. } \\
\text { Working machine }\end{array}$ & $\begin{array}{l}\text { L } \\
M \\
\text { S-L } \\
\text { S-L } \\
M \\
L \\
M \\
\text { S-L } \\
\text { L }\end{array}$ & 99.4 & $\begin{array}{r}3.65 \\
10.00 \\
3.20 \\
3.10 \\
10.005 \\
3.605 \\
+10.005 \\
3.255 \\
3.55\end{array}$ \\
\hline $\begin{array}{l}1 \cdot 59-2 \cdot 07 \\
2 \cdot 07-2 \cdot 15 \\
2 \cdot 15-2 \cdot 30 \\
2 \cdot 30-2 \cdot 59\end{array}$ & $\begin{array}{r}8 \\
8 \\
15 \\
29\end{array}$ & $\begin{array}{l}83 \cdot 0 \\
83 \cdot 0 \\
85 \cdot 0 \\
86 \cdot 0\end{array}$ & $\begin{array}{l}109 \cdot 0 \\
109 \cdot 0 \\
111 \cdot 0 \\
\text { II } 2 \cdot 0\end{array}$ & $\begin{array}{l}\text { II3 } \\
\text { I13 } \\
\text { II2 } \\
\text { II2 }\end{array}$ & $\begin{array}{l} \pm 300 \\
\pm 300 \\
\pm 300 \\
\pm 100\end{array}$ & $\begin{array}{l}\text { Working machine } \\
\text { Standing } \\
\text { Working machine } \\
\text { Working on rope of machine }\end{array}$ & $\begin{array}{l}\text { L } \\
\text { S-L } \\
\text { L } \\
\text { L }\end{array}$ & $99 \cdot 0$ & $\begin{array}{l}3.55 \\
3.05 \\
3.55 \\
3.55\end{array}$ \\
\hline $\begin{array}{r}2 \cdot 59-3 \cdot 08 \\
3 \cdot 08-3 \cdot 15 \\
3 \cdot 15-4 \cdot 03\end{array}$ & $\begin{array}{r}9 \\
7 \\
48\end{array}$ & $\begin{array}{l}87 \cdot 0 \\
73 \cdot 0\end{array}$ & $\begin{array}{l}113 \cdot 0 \\
87 \cdot 0\end{array}$ & $\begin{array}{l}114 \\
-\end{array}$ & $\begin{array}{l} \pm 50 \\
\pm 50\end{array}$ & $\begin{array}{l}\text { Working on rope at machine } \\
\text { Travelling to crib room } \\
\text { Crib room }\end{array}$ & $\begin{array}{l}\mathbf{L} \\
-\end{array}$ & & $\begin{array}{l}4 \cdot 70 \\
-\end{array}$ \\
\hline $\begin{array}{r}4 \cdot 03-4 \cdot 08 \\
4 \cdot 08-4 \cdot 20 \\
4 \cdot 20-4 \cdot 27 \\
4 \cdot 27-4 \cdot 36 \\
4 \cdot 36-4 \cdot 47 \\
4 \cdot 47-4 \cdot 56 \\
4 \cdot 56-4 \cdot 58 \\
4 \cdot 58-5 \cdot 04 \\
\text { End of } 5 \text { th ho }\end{array}$ & $\begin{array}{r}5 \\
12 \\
7 \\
9 \\
11 \\
10 \\
2 \\
2 \\
6\end{array}$ & $\begin{array}{r}87 \cdot 0 \\
85 \cdot 0 \\
97 \cdot 0 \\
101 \cdot 0 \\
87 \cdot 0 \\
86 \cdot 0 \\
101 \cdot 0\end{array}$ & $\begin{array}{l}-\overline{0} \\
\text { II4.0 } \\
111 \cdot 0 \\
122 \cdot 0 \\
120 \cdot 0 \\
114 \cdot 0 \\
114 \cdot 0 \\
120 \cdot 0\end{array}$ & $\begin{array}{l}- \\
\text { II4 } \\
\pm 112 \\
\pm 125 \\
- \\
\text { I14 } \\
\text { II4 }\end{array}$ & $\begin{array}{l} \pm \\
\pm 200 \\
\pm 300 \\
\pm 20 \\
- \\
\pm 250 \\
\pm 250\end{array}$ & $\begin{array}{l}\text { Travelling from crib room to working place } \\
\text { Standing } \\
\text { Working machine } \\
\text { Working at machine with crowbar } \\
\text { Pulling rope along drive } \\
\text { Standing behind machine in air flow } \\
\text { Working machine } \\
\text { Pulling rope, etc. }\end{array}$ & $\begin{array}{l}\overline{S-L} \\
\mathbf{L} \\
\mathrm{L} \\
\mathrm{M}-\mathrm{H} \\
\text { S-L } \\
\text { M }\end{array}$ & $\begin{array}{l}100 \cdot 6 \\
100 \cdot 6\end{array}$ & $\begin{aligned} & 3.2 \\
& 3 \cdot 55 \\
\pm & 10 \cdot 00 \\
\pm & 10 \cdot 00 \\
& \pm 10.00\end{aligned}$ \\
\hline
\end{tabular}

Note Because of temperature conditions this was classified as a six-hour job.

$\star \mathcal{S}=$ sitting; $\mathrm{L}=$ light rate of work; $\mathbf{M}=$ moderate rate of work; $\mathrm{H}=$ hard rate of work. 


\section{APPENDIX 2}

The present study was initiated to determine the relative effects on $P_{4} S R$ values of the various independent variables over the ranges in which they occur in the mine at Mount Isa.

Procedure Initial data were obtained from the $\mathrm{P}_{4}$ SR nomogram by selecting the five independent variables, metabolic rate $(M)$, globe temperature (G.T.), dry bulb temperature (D.B.), air velocity (W.V.) and wet bulb temperature (W.B.) at each of three levels. Thus the data represented a $3^{5}$ factorial experiment.

The levels chosen for each of the independent variables were:

Metabolic rate

75, 125 , and $175 \mathrm{Cal} . / \mathrm{m} .^{2} / \mathrm{hr}$.

Globe temperature

104, 106, and $108^{\circ} \mathrm{F}$.

Dry bulb temperature

96,100 , and $104{ }^{\circ} \mathrm{F}$.

Air velocity

50,200 , and $500 \mathrm{ft} . / \mathrm{min}$.

Wet bulb temperature

80,84 , and $88{ }^{\circ} \mathrm{F}$.

The modified W.B. of the $B_{4} S R$ nomogram was calculated from persons wearing shorts only; i.e.,

$\mathrm{MW}=\mathrm{W} . \mathrm{B}$. +0.4 (G.T. - D.B.) + Factor to

be added from W.B. on $M$ chart.

The $\mathrm{P}_{4} \mathrm{SR}$ was obtained from the $\mathrm{B}_{4} \mathrm{SR}$ by the addition of the factor, $0.014(M-54)$.

With the variables at the above levels, the range of $P_{4} S R$ values covered is from $I \cdot 39$ to $8 \cdot 69$.

Analysis An analysis of variance indicated that a second order equation may be used to explain the relationship of the $\mathrm{P}_{4} \mathrm{SR}$ to the independent variables. Thus far, only second-degree equations have been fitted to the results. The most promising equation found to date is:

$$
\begin{aligned}
& \mathbf{P}_{4} \mathbf{S R}=-0.13155 \mathrm{M}-0.0000508 \mathrm{M}^{2}+ \\
& 0.000877 \text { G.T. } \times M \\
& +0.0003399 \text { G.T. }{ }^{2}+\text { I.6520 D.B. - } \\
& 0.0008392 \mathrm{M} \times \text { D.B. } \\
& +0.01622 \text { W.V. }-0.00001337 M \times \\
& -0.00006755 \text { G.T. } \times \text { W.V. }+ \\
& 0.0001188 \text { D.B. } \times \text { W.V. } \\
& +0.000007532 \text { W.V. } .^{2}+0.001925 M \times \\
& \text { - } 0.01977 \text { D.B. } \times \text { W.B. - } \\
& 0.000291 \text { I W.V. } \times \text { W.B. } \\
& +0.01189 \text { W.B. } .^{2}-87 \cdot 4005 \text {. }
\end{aligned}
$$

This equation is a formidable one. However, it must be remembered that we are dealing with a complex subject.

The correlation coefficient obtained when fitting this equation to the data was 0.9795 . Thus the equation accounts for some $96 \%$ of the variation in $\mathbf{P}_{4}$ SR observed.

By taking partial derivatives of the above equation with respect to each of the independent variables, it is possible to determine the relative contributions to a change in the $\mathrm{P}_{4} S R$.

These partial derivatives are:

$$
\begin{aligned}
& \frac{\partial \mathrm{P}_{4} \mathrm{SR}}{\partial \mathrm{M}}=\frac{-0.0001016 \mathrm{M}}{0.0008392 \text { D.B. }-0.000001337 \text { W.V. }}+ \\
& 0.001925 \text { W.B. - } 0.1316 \\
& \frac{\partial P_{4} S R}{\partial G . T .}=0.000877 M+0.0006798 \text { G.T. }- \\
& 0.00006755 \text { W.V. } \\
& \frac{\partial \mathrm{P}_{4} \mathrm{SR}}{\partial \mathrm{D} . \mathrm{B} .}=0.0008392 \mathrm{M}+0.0001 \mathrm{r} 88 \mathrm{~W} . \mathrm{V} .- \\
& 0.01977 \text { W.B. }+ \text { I.6520 } \\
& \frac{\partial P_{4} S R}{\partial W . V .}=-\frac{0.00001337 M-0.00006755 \text { G.T. }+}{0.0001188 \text { D.B. }+0.0000147 \text { W.V. }-} \\
& 0.0002911 \text { W.B. + } 0.01622
\end{aligned}
$$

It should be remembered that, as the original equation is of the second order, the values of the partial derivatives depend very much on the conditions.

Considering first the centre of the range investigated, substitution of the following values for the independent variables will give the change in $\mathrm{P}_{4} \mathrm{SR}$ for a one-unit change in the variable concerned in the partial derivative.

At $M=125$, G.T. $=106$, D.B. $=100$, W.V. $=$ 200, and W.B. $=84$

$$
\begin{aligned}
& \frac{\partial \mathbf{P}_{\mathbf{4}} \mathbf{S R}}{\partial \mathbf{M}}=0.02377 \\
& \frac{\partial \mathbf{P}_{\mathbf{4}} \mathbf{S R}}{\partial \mathrm{G} . \mathrm{T} .}=0.1682 \\
& \frac{\partial \mathbf{P}_{\mathbf{4}} \mathrm{SR}}{\partial \mathbf{D} . \mathrm{B} .}=-0.08982 \\
& \frac{\partial \mathbf{P}_{\mathbf{4}} \mathrm{SR}}{\partial \mathbf{W} . \mathrm{V} .}=-0.002294 \\
& \frac{\partial \mathbf{P}_{\mathbf{4}} \mathrm{SR}}{\partial \mathbf{W} . \mathrm{B} .}=0.2029
\end{aligned}
$$

The equations indicate that, at the centre of the range investigated,

An increase in the metabolic rate of $\mathrm{I} \mathrm{Cal.} / \mathrm{m} .{ }^{2} / \mathrm{hr}$ will increase the $P_{4} S R$ by 0.02 , 
TABLE

Change IN G.T. AND W.B. Necessary to PRODUCE A UNIT INCREASE IN P.SR

\begin{tabular}{|c|c|c|c|c|c|c|c|c|c|}
\hline & \multicolumn{3}{|c|}{$G . T .=104^{\circ}$} & \multicolumn{3}{|c|}{$G . T .=106^{\circ}$} & \multicolumn{3}{|c|}{$G . T .=108^{\circ}$} \\
\hline & $\underset{96^{\circ}}{D . B .}=$ & $\underset{100^{\circ}}{D . B .}=$ & $\underset{104^{\circ}}{D . B .}=$ & $\underset{96^{\circ}}{D . B .}=$ & $\underset{100^{\circ}}{D . B .}=$ & $\underset{104^{\circ}}{D . B .}=$ & $\underset{96^{\circ}}{D . B .}=$ & $\underset{100^{\circ}}{D . B .}=$ & $\underset{104^{\circ}}{D . B .}=$ \\
\hline W.B. $=80$ & $\begin{array}{l}6 \cdot 00 \\
5.35\end{array}$ & $\begin{array}{l}6 \cdot 00 \\
9 \cdot 28\end{array}$ & $\begin{array}{r}6.00 \\
34.81\end{array}$ & $\begin{array}{l}5 \cdot 90 \\
5 \cdot 35\end{array}$ & $\begin{array}{l}5 \cdot 90 \\
9 \cdot 28\end{array}$ & $\begin{array}{r}5.90 \\
34.81\end{array}$ & $\begin{array}{l}5.90 \\
5.35\end{array}$ & $\begin{array}{l}5 \cdot 90 \\
9 \cdot 28\end{array}$ & $\begin{array}{r}5 \cdot 90 \\
34 \cdot 81\end{array}$ \\
\hline W.B. $=84$ & $\begin{array}{l}6.00 \\
3.55\end{array}$ & $\begin{array}{l}6.00 \\
4.93\end{array}$ & $\begin{array}{l}6 \cdot 00 \\
8 \cdot 07\end{array}$ & $\begin{array}{l}5.90 \\
3.55\end{array}$ & $\begin{array}{l}5.90 \\
4.93\end{array}$ & $\begin{array}{l}5.90 \\
8.07\end{array}$ & $\begin{array}{l}5.90 \\
3.55\end{array}$ & $\begin{array}{l}5.90 \\
4.93\end{array}$ & $\begin{array}{l}5.90 \\
8.07\end{array}$ \\
\hline W.B. $=88$ & $\begin{array}{l}6.00 \\
2.65\end{array}$ & $\begin{array}{l}6 \cdot 00 \\
3 \cdot 36\end{array}$ & $\begin{array}{l}6 \cdot 00 \\
4 \cdot 57\end{array}$ & $\begin{array}{l}5.90 \\
2.65\end{array}$ & $\begin{array}{l}5 \cdot 90 \\
3 \cdot 36\end{array}$ & $\begin{array}{l}5 \cdot 90 \\
4 \cdot 57\end{array}$ & $\begin{array}{l}5.90 \\
2.65\end{array}$ & $\begin{array}{l}5 \cdot 90 \\
3 \cdot 36\end{array}$ & $\begin{array}{l}5 \cdot 90 \\
4.57\end{array}$ \\
\hline
\end{tabular}

(Upper value is G.T., lower is W.B., both in ${ }^{\circ} \mathrm{F}$.)

Further, where there are appreciable differences between the G.T and D.B. at moderate humidities, the effects of G.T. and W.B. are similar. It is only when high humidities are coupled with this appreciable difference that the effect of W.B. is increased.

An increase in the globe temperature of $I^{\circ} \mathrm{F}$. will increase the $\mathrm{P}_{4} \mathrm{SR}$ by 0.17 ,

An increase in the dry bulb temperature of $I^{\circ} \mathrm{F}$. will decrease the $\mathrm{P}_{4} \mathrm{SR}$ by 0.09 ,

An increase in the wind velocity of $\mathrm{I} f \mathrm{ft}$. $/ \mathrm{min}$. will decrease the $\mathrm{P}_{4} \mathrm{SR}$ by 0.002 , and

An increase in the wet bulb temperature of $I^{\circ} \mathrm{F}$. will increase the $P_{4} S R$ by 0.20 .

Thus the nomogram indicates that while globe temperature and wet bulb temperature have a marked effect on the $\mathrm{P}_{4} \mathrm{SR}$, the effect of a change in wind velocity is almost negligible.

Of particular interest are the effects of changes in the W.B. and G.T. It is to be noted that these give rise to nearly the same effect (0.20 cf. 0.17$)$ which is not in accordance with claims made by Macpherson (1960).

A more comprehensive illustration of the effects of G.T. and W.B. is given in the Table. These values have been calculated with the $M$ rate and W.V. kept constant at 125 and 200 respectively. The upper value of each of the two entries for each position is the increase in G.T. necessary to produce a unit increase in the $P_{4} S R$. It should be observed from the Table that the effect of G.T. is sensibly constant throughout the range, whereas it is only when high humidities are coupled with an appreciable difference between G.T. and D.B. that the effect of W.B. on $\mathrm{P}_{4} \mathrm{SR}$ is marked.

\section{REFERENCES}

Bedford, T. (1946). War Memor. No. 17, Med. Res. Coun. (Lond.).

Belding, H. S., and Hatch, T. F. (1955). Heat, Piping, Air Condit., 27, no. 8 (August) p. 129.
Dunham, W., Holling, H. E., Ladell, W. S. S., McArdle, B., Scott, J. W., Thomson, M. L., and Weiner, J. S. (1946). The effect of air movement in severe heat. R.N.P.R.C. Rep. No. 46/316, Med. Res. Coun. (Lond.).

Eichna, L. W., Ashe, W. F., Bean, W. B., and Shelley, W. B. (1945). 7. industr. Hyg., $27,59$.

Ferris, H. M., Fox, R. H., Jack, J. W., John, R. T., Lind, A. R., Macpherson, R. K., and Newling, P. S. B. (1954). Physiological responses to hot environments of young European men in the tropics. V. The effect of increasing the mean radiant temperature of the surroundings. R.N.P.R.C. Report No. $54 / 812$, Med. Res. Coun. (Lond.).

Haldane, J. S. (1905). F. Hyg., 5, 494.

Lavenne, F. (1965). Rev. Inst. Hyg. Mines, 20, 3.

Lind, A. R. (1960). Industr. Med. Surg., 29, 515.

- (1963). F. appl. Physiol., 18, 5 I.

Macpherson, R. K. (1960). Spec. Rep. Ser. med. Res. Coun. (Lond.)., 298.

- (1962). Brit. F. industr. Med., 19, 15 I.

Nielsen, M. (1938). Skand. Arch. Physiol., 79, 193.

Robinson, S., Turrell, E. S., and Gerking, S. D. (1945). Amer. F. Physiol., 143, 21.

Smith, F. E. (1955). Med. Res. Coun. Memo No. 29.

Strydom, N. B., Morrison, J. F., Booyens, J., and Peters J. (1956). F. appl. Physiol., 8, 406.

-, Wyndham, C. H., Williams, C. G., Morrison, J. F., Bredell, G. A. G., and Joffe, A. (1965). F. appl. Physiol., 20, 283.

Weiner, J. S., and Lind, A. R. (1955). The Manager (Lond.)., 23, 853 .

Winer, P., Maritz, J. S., and Wyndham, C. H. (1962). Nature (Lond.), 193, 848.

Wyndham, C. H. (1965a). F. appl. Physiol., 20, 31 .

(1965b). F. S.A. Inst. Min. Metall., 66, 125.

- - Bouwer, W. v.d. M., Devine, M. G., and Patterson, H. F. (1953). F. Chem. Met. Min. Soc. (S.A.), 53, 287.

- Strydom, N. B., Morrison, J. F., Williams, C. G., Bredell, G. A. G., Maritz, J. S., and Munro, A. H. (I965). F. appl. Physiol., 20, 37.

,$--\longrightarrow$, Munro, A. H., Heyns, A., and Sichel, H. B. (1966). Research Report No. 62-66, Chamber of Mines, Johannesburg. 
-how to start and when to stop-and explains the special psychological atmosphere of general practice.

Section 3 presents conclusions. The result of five years' research is a number of problems, awkward and uncomfortable. Advice by the doctor is usually a well intended shot in the dark, nearly always futile, as is reassurance.

General practice is seriously ill with a benign disease and if the right therapy is applied the prognosis is good. The present symptoms of malaise in general practice are of the doctors' own making, and Dr. Balint believes that he has presented the symptoms and diagnosis of this malady and urges doctors to try to effect a radical cure.

An appendix gives hints to psychiatrists who are taking general practitioners in refresher courses on the selection of general practitioners for these courses and follow up details of the patients discussed in the seminars at the Tavistock Clinic.

It is disappointing that the book raises more problems than it answers and gives little advice. It certainly does not give short cuts or simple rules to lessen the burden of the 'neurotic' patient in general practice.

Not everyone will accept Balint's teaching, and it will cause antagonism among many. Some will still believe in shutting the door firmly on the neurotic skeleton in the cupboard as being the most economical way of dealing with this problem.

The book should be compulsory reading for all students, specialists, and general practitioners.

H. W. ASHWORTH

\section{NOTICES}

\section{Asian Conference on Occupational Health}

The Vth Asian Conference on Occupational Health will be held in Bombay (India) in November 1968. The Conference will be attended by experts on various aspects of occupational health from many parts of the world.

Scientific discussions will be held on various subjects pertaining to occupational health, such as Safety in Industry, Industrial Hygiene, and Ergonomics.

For further information please write to Dr. J. C. Kothari, Secretary-General, P.B. No. 355, Bombay, India.

\section{The British Occupational Hygiene Society}

A Third International Symposium on Inhaled Particles is to be held in September 1970 in the United Kingdom (provisionally at the Imperial College of Science and Technology, London). It is a sequel to the earlier symposia held at Oxford in 1960 and at Cambridge in 1965 .
This conference, whilst maintaining the previous general theme of the advances in knowledge of the mechanisms governing the entry of foreign material into the lungs and the response of the lungs to inhaled matter, will concentrate on the application of this basic knowledge to the particular problems of coal-workers' and industrial mixed dust pneumoconiosis.

Contributions to the Symposium will be welcome from all countries. They should in general describe original research but some review papers will be accepted. Contributions will be subject to scrutiny by the Society's Honorary Editor with the assistance of an advisory panel.

The Symposium is expected to last $4 / 5$ days; simultaneous translation will be provided in English, French, and German (and other languages, depending on requirements). The proceedings will subsequently be published in book form, full details of which will be announced later.

Persons wishing to receive further details and/or to present contributions should write to the Secretary of the Organizing Committee: Dr. J. S. McLintock, Medical Service, National Coal Board, Hobart House, Grosvenor Place, London, S.W.r.

\section{Second Scottish Symposium on Colour}

Organized by the Colour Group (Scottish Section) and the Visual Laboratory of the Department of Psychology, Edinburgh University, the Symposium will be held in the David Hume Tower, Edinburgh University, George Square, Edinburgh, on Thursday and Friday, 5 and 6 September, 1968. Further information may be obtained from the Hon. Secretary, R. S. Sinclair, Paisley College of Technology, Paisley, Scotland.

\section{CORRECTIONS}

In the paper 'The Diagnosis of Industrial Lead Poisoning' by Gibson, Mackenzie, and Goldberg (Brit. F. industr. Med., 1968, 25, 40-5I) reference was made in Table III on p. 47 to the findings of Cramér and Selander on the correlation between urinary ALA and PBG and clinical manifestations. This was incorrect, for in the paper by Cramér and Selander which was quoted there were no data on the urinary excretion of PBG.

In the paper 'Assessing the Heat Stress and Establishing the Limits for Work in a Hot Mine' by Wyndham, Allan, Bredell, and Andrew (Brit. F. Industr. Med., 1967, 24, 255-27I), line 3 on p. 264 should read "This statement means that the same effect on $P_{4} S R$ values is seen from a $10^{\circ} \mathrm{F}$. change in D.B. and a $30^{\circ} \mathrm{F}$. change in G.T." 